\title{
Guidelines and tools to design and manage properly dam-reservoir systems
}

\author{
J. S. Antunes do Carmo \& R. F. Carvalho \\ IMAR, University of Coimbra, Department of Civil Engineering, \\ Pólo II of the University, Coimbra, Portugal
}

\begin{abstract}
The high costs associated with the building of a dam, as well as the material and human damage which would result if it failed, make it essential that careful studies should be carried out on natural accidents and their consequences, which can endanger these constructions. Natural hazards such as floods, earthquakes and landslides are important contributors to risk. The integrated study of these phenomena is therefore unquestionably something which must be considered in the project phase of a dam, especially when the construction site is placed in a high risk seismic activity zone, or when geological studies of the banks indicate the existence of potential landslide areas. Human behaviour is another element of dam failure risk: errors, simple mistakes, operational mismanagement or unnecessary oversights can interact with other hazards to compound the possibility of failure. Thus, there is a broad range of natural and human hazards which, taken separately or in combination, increase the probability of dam failure and injury to people and property. Risk analysis involves the consideration of a number of hazards and scenarios. Such analyses are helpful in stimulating better awareness, planning and design. Adding to the risks resulting from hydrology large-scale flooding, landslides and earthquake movements, other risks tend to result from design errors, construction aspects and operating problems. Risk management includes risk control and mitigation in order to avoid risks increasing with the passage of time.

Keywords: dam-reservoir systems, floods management, earthquakes, landslides, laboratory experiments.
\end{abstract}




\section{Introduction}

Dams are built for many purposes: water storage for potable water supply, livestock water supply, irrigation, fire-fighting, flood control, recreation, navigation, hydroelectric power or simply to contain mine tailings. Dams may also be multifunctional, serving two or more of these purposes. However, large reservoirs constructed near urban areas have a high potential risk for life and property downstream.

The total risk for dam structures mainly depends on two factors: $i$ ) Natural hazards such as floods, earthquakes and landslides, and ii) Human behaviour, errors, simple mistakes and operational mismanagement. Improving the understanding of realistic risks and possible reasons for dam failure is an essential first step in any overall effort to improve dam safety and risk management (Almeida et al. [1]; Almeida and Viseu, [2]), as well as to preserve the benefits of dam ownership. In order to achieve a sustainable valley development an integrated valley management should consider environmental safety and risk as well as economic and ethical aspects.

There are many complex reasons for a dam failure - both structural and nonstructural. Many sources of failure can be traced to decisions made during the design and construction process and to inadequate maintenance or operational mismanagement. Failures have also resulted from anthropogenic causes, which include: poor quality of construction and construction materials; improper reservoir management, and acts of war. Any of these factors may lead to the total or partial destruction of the dam, and to the formation of a devastating tidal wave.

\section{General impact of earthquakes on dams and its evaluation}

Dams exhibit remarkable longevity, and currently have a good safety record compared with other structures. In fact, the annual probability of a dam failure is estimated at $10^{-4}$ and the probability of failure during the lifetime of a dam (100 years) is $10^{-2}$. Nevertheless, considering both the partial and total breaks reported in the literature, and the potential magnitude of the ever-present possibility of catastrophe, the problem merits study.

The values of the maximum hydrodynamic pressure, particularly when resulting from vertical and longitudinal ground motions are often greater than $50 \%$ of the corresponding hydrostatic pressure values. Additionally, seismic activity in reservoirs can cause large waves that will overtop the dam. Floods resulting from the rupture of a dam can have very serious and unpredictable consequences for populations located downstream from the dam.

The dynamic behaviour of a dam is strongly influenced by water mass-dam interaction and by reflection/damping of the hydrodynamic pressure waves on the dam, banks and reservoir bottom. The dynamic pressure on a dam, caused by an earthquake has to be obtained. Assuming some hypothesis for the fluid, the water motion and the waves produced, it can be shown that the motion of the 
fluid is governed by the Helmholtz equation (1) for the pressure $\bar{p}$ (where $c \approx 1440 \mathrm{~ms}^{-1}$ and $w$ is the frequency of the motion).

$$
\frac{\partial^{2} \bar{p}}{\partial x^{2}}+\frac{\partial^{2} \bar{p}}{\partial z^{2}}+\left(\frac{w}{c}\right)^{2} \bar{p}=0
$$

Equation (1) can be solved using an efficient numerical formulation based on boundary elements (Hanna and Humar, [9]).

As an example of its application, the hydrodynamic pressure diagrams due to a ground horizontal motion with a frequency $w=18.85 \mathrm{rads}^{-1}$ acting on the upper face of a dam, considering a reservoir bottom slope $\beta=0^{\circ}$ (horizontal) and four distinct configurations of this face, is presented in Figure 1 below.

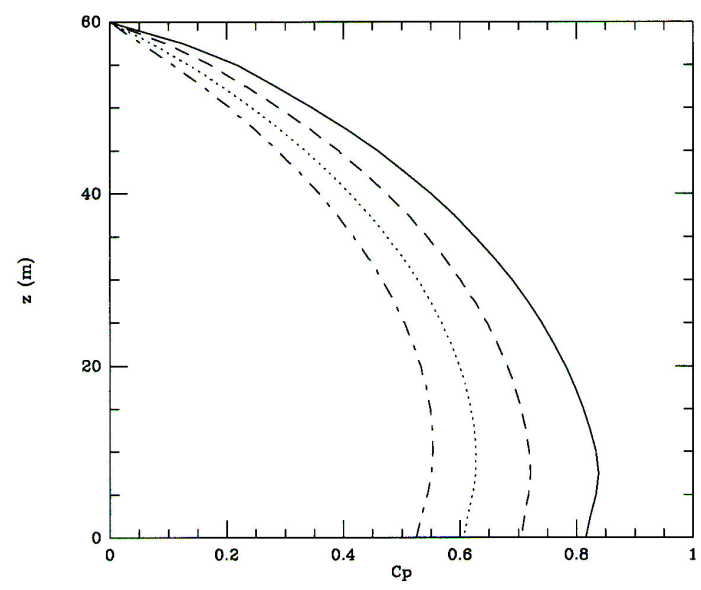

Figure 1: Hydrodynamic pressure diagrams considering a reservoir horizontal bottom $\beta=0^{\circ}$ and four cases for the upper face of the dam: $\theta=0^{\circ} \quad($ vertical face, -$) ; 11.3^{\circ}(--) ; \quad 21.8^{\circ}(\cdots)$ and $31.0^{\circ}(-\cdot-)$.

In Figure $1 C_{p}=\sum_{i=1}^{\infty} \frac{A_{i}}{H} e^{-\lambda_{i} x} \cos \left(-\lambda_{i} z\right)$, where $H$ is the reservoir water depth close to the dam, and $A_{i}$ is the coefficient to be determined observing the condition $\left.\frac{\partial p}{\partial n}\right|_{s}=-\rho \ddot{a}_{g}(t) \cos (\theta)$, where $\ddot{a}_{g}$ is the horizontal acceleration of the ground motion and $\theta$ the angle between the $x$-axis and the normal to the face of the dam. Knowing the $C_{p}$ coefficients, the hydrodynamic pressure is obtained by $\bar{p}(x, z)=\rho H \ddot{a}_{g} C_{p}$.

Clearly, the shape or configuration of the upper face of a dam has a crucial effect on the magnitude of the total hydrodynamic force acting on the dam. This 
analysis is easily extended to compound configurations of that face (different slopes), as well as to real bathymetries of the reservoir bottom.

\section{Landslides into reservoirs}

\subsection{General effects and risk evaluation}

Landslides can cause devastating damage. The degree of impact of slides depends mainly on the volume and speed of the mass, but also on the extent of the unstable area and the disaggregation of the moving mass. The most common slides are: rock falls from escarpments of highly fractured rocky masses; soil slides on slopes; mud flows, avalanches, and debris falls that can travel great distances along valleys and river channels; and creep that can cover huge surfaces. The most dangerous are those that occur suddenly and at high speeds (rock falls, flows, and avalanches). There are usually warning signs for landslides (cracks, soil undulation, etc.); they can occur suddenly or very gradually, and move quickly or very slowly.

The risk of slope failure into a reservoir should first be evaluated using geological information complemented with remote sensing techniques. In terms of geological information, the lithology, the geomorphology, the geological structure and the stress on the existing or potential shear zones, are extremely important in the development of the failure movements of slopes. Only with a detailed field survey is it possible to evaluate the local geological characteristics prone to slope instability on the banks of reservoirs. The geological information must be analysed together with the water level fluctuations in the reservoir, and with other external actions promoting slope instability, like rain, water or earthquakes. According to Fritz et al. [8], the characteristics of the wave packets generated by landslides are dependent of the following factors: $i$ ) the sliding mass volume; $i$ ) the sliding mass velocity at the moment of impact, which will be dependent on the out of unbalanced forces/moments, themselves influenced by the dynamic properties of soil, by soil brittleness and by topographic effects, and iii) the reservoir size, or volume, and depth.

Experimental studies of impulse waves generated by landslides composed by granular rockslide can be found in Fritz et al. [8]. According to these studies, four wave types were determined: weakly nonlinear oscillatory, nonlinear transition and solitary wave. Fritz et al. [8] proposed several empirical formulas to predict the wave characteristics, based on three fundamental dimensionless parameters. Lynett and Liu [10] examine numerically the maximum run-up at a beach, generated by submerged and subaerial solid body landslides. They found some interesting results, which could be useful for preliminary hazard assessment, particularly for the maximum run-up and locations. Carvalho and Antunes do Carmo [6] examined the wave propagation and its impact on a dam by means of laboratory measurements and numerical models with different approaches. Among their conclusions was that more experiments are needed to improve and detail the measurements that lead to the slide mass velocity function during the fall, to allow a better numerical solution. 


\subsection{Zonation maps showing risk areas}

There are many factors that bring about landslides, and there is still uncertainty as to their predictability, the speed at which they occur, and area affected. However, there are certain parameters that help to identify and recognize potential areas of failure, and which allow measures to reduce the risk of slope failure. Using scales of 1:25000 to 1:50000, important evidence can be collected about ongoing slides, which should be evaluated on site after an aerial survey.

In general, areas where slides have occurred in the past are highly susceptible to recurring slides. Information sources include reports about landslides in the local press and zonation maps showing areas of geologic instability, inventories of geologic risks, etc. Among the main sources of information, the geology of a region and topographic maps are clearly very useful for producing zonation maps showing risk areas. Indeed, knowledge of the geology and topography of an area assists in estimating the susceptibility of slopes to movement. Topographic and geological maps are excellent sources of information for detecting landslides, particularly for extensive slide areas. Areas where landslides occur frequently can be identified and specific conditions can be analysed.

Rainfall, erosion processes and earthquakes are all important factors that can lead to the instability of slopes. Rainfall has a strong effect on the stability of slopes by influencing the shape, incidence, and extent of slides. Rainfall can saturate residual soils, thereby activating slides. Erosion is the result of natural and human activities. Natural agents include: water runoff, ground water, waves, currents, and wind. Human activity that causes erosion includes anything that produces increased water velocity, especially on unprotected slopes. Among the leading causes are deforestation, forest fires, over-grazing of pasture, and the presence of certain types of vegetation that do not increase the soil's resistance to erosion. Slope failure and soil liquefaction are among the effects of earthquakes that can cause major material and human losses. Most slope failures during earthquakes result from the liquefaction of non-cohesive soils. However, failures in cohesive soils have also been observed during seismic events.

\subsection{Physical characterization and numerical modelling of the formation and propagation of waves caused by landslides}

A conceptual mathematical model is suggested for the slide impact and its evolution into the water mass. The resulting waves are tested and different instants of its propagation are compared with experimental laboratory results. For this, masses of different materials displaced by sliding over a bank placed on a channel $1 \mathrm{~m}$ wide were reproduced in the laboratory (Carvalho and Antunes do Carmo, [6]). Different combinations of reservoir depths, mass volumes, mass centre positions and sliding angles of the bank were studied.

A video camera was used to characterize the movement and velocity evolution of the mass sliding into the water. This analysis allowed us to obtain a function of the type $M=f(t)$, which has been used to find a solution of an equation for the movement of a non-deformable block, using a $4^{\text {th }}$ Runge-Kutta method. 


\subsubsection{Laboratory installation and equipment}

The channel of the laboratory installation is $40.0 \mathrm{~m} \times 1.5 \mathrm{~m} \times 1.0 \mathrm{~m}(\mathrm{~L} \times \mathrm{H} \mathrm{x} \mathrm{W})$; the variable sloping bank and the dam were placed along a length of approximately $12 \mathrm{~m}$. The landslide was reproduced in the laboratory installation by calcareous masses that fell by sliding over the bank. The bank was made of acrylic glass measuring $2.510 \mathrm{~m} \times 0.010 \mathrm{~m} \times 0.992 \mathrm{~m}$, supported by a metallic structure which allowed the slope angle to vary between $30^{\circ}$ and $45^{\circ}$. On the bank, at positions $0.95 \mathrm{~m}$ and $1.05 \mathrm{~m}$ away from the bottom, a gate was placed to retain the calcareous material. The gate was also made of acrylic glass and measured $0.510 \mathrm{~m} \times 0.010 \mathrm{~m} \times 0.980 \mathrm{~m}$ and moved in two U gutters, connected in a guide pulley system to a counter balance. The falling of the counter balance caused the gate to rise, and so the material slide. Sliding masses were simulated by several calcareous blocks, measuring $0.07 \mathrm{~m} \times 0.08 \mathrm{~m} \times 0.10 \mathrm{~m}$, density $\rho_{S} / \rho=2.38$ and porosity $\eta_{\text {por }} \approx 0.40$.

Figure 2 shows the mechanism that allows the material to slide over the bank and the calcareous mass retained by the gate.
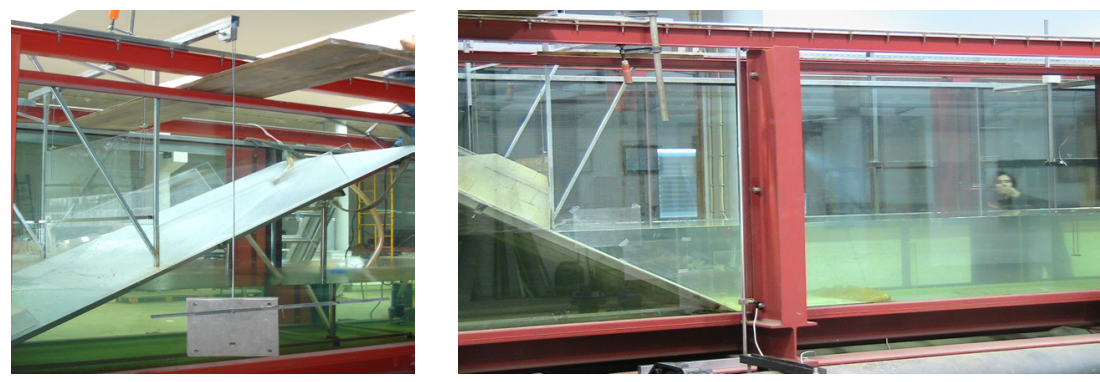

Figure 2: View of the mechanism that allows the material to slide over the bank and the calcareous mass sustained by the gate.

Different parameters were tested: two values for the sliding mass volume; two values for the gate position, for avoiding two different high falls; two values for the variable bank slope, and four values for the variable water depth. For both volumes of $0.0814 \mathrm{~m}^{3}$ and $0.168 \mathrm{~m}^{3}$, corresponding to masses of $193.29 \mathrm{~kg}$ and $400.85 \mathrm{~kg}$, respectively, mass centers were calculated for two bank slopes $\left(30.7^{\circ}\right.$ and $\left.39.5^{\circ}\right)$ and gate positions $(61.5 \mathrm{~cm}$ and $71.5 \mathrm{~cm})$. Table 1 illustrates the different parameters tested. The reservoir water level varied between $0.30 \mathrm{~m}$ and $0.55 \mathrm{~m}$. The friction angle was determined experimentally. For the two volumes, $0.0814 \mathrm{~m}^{3}$ and $0.168 \mathrm{~m}^{3}$, friction slopes of $\phi \approx 23.83^{\circ}$ and $\phi \approx 26.02^{\circ}$ were obtained with a correlation greater than 0.99 .

The movement of the sliding mass, from the initial position to its final position, was filmed using a video-camera. The images were subsequently analyzed to obtain an estimate of the submerged mass and volume as a function of time, that is $M=f(t)$. This knowledge was required to solve equation (2), which describes the movement of the sliding block: 
Table 1: Mass centre positions for different experiments (Carvalho et al. [7]).

\begin{tabular}{cccc}
\hline $\begin{array}{c}\text { gate position } \\
(\mathrm{cm})\end{array}$ & $\begin{array}{c}\text { slide slope } \\
\left({ }^{\circ}\right)\end{array}$ & $\begin{array}{c}\text { mass volume } \\
\left(\mathrm{m}^{3}\right)\end{array}$ & $\begin{array}{c}\text { height of the c. of gravity } \\
(\mathrm{cm})\end{array}$ \\
\hline 51.5 & 30.7 & 0.0814 & 74.15 \\
61.5 & 30.7 & 0.0814 & 84.16 \\
51.5 & 30.7 & 0.1687 & 85.08 \\
51.5 & 39.5 & 0.0814 & 76.60 \\
61.5 & 39.5 & 0.0814 & 86.60 \\
51.5 & 39.5 & 0.1687 & 89.97 \\
\hline
\end{tabular}

$$
M \frac{d v_{s}}{d t}=M g \sin \alpha-M_{w} g \frac{\rho_{s}}{\rho_{w}} \sin \alpha-M g \cos \alpha \tan \phi-\frac{1}{2} C_{d} \rho_{w} A v_{s}^{2}
$$

where $M$ is the mass of the sliding block, $M_{w}$ is the submerged mass, $v_{s}$ is the slide mass velocity, $\alpha$ is the bank slope, $\phi$ is the friction slope, $\rho_{s}$ is the density of slide mass, $\rho_{w}$ is the water density, $C_{d}$ is the drag coefficient for the slide, $A$ is the slide mass section, $t$ is the time and $g$ is the acceleration due to gravity. Equation (2) was solved with a $4^{\text {th }}$ Runge-Kutta. Between the sliding bank and the dam, five probes (HR Wallingford wave probe monitors $0.60 \mathrm{~m}$ ) were positioned 2, 4, 6 and $8 \mathrm{~m}$ away from the bank to measure the water level variation. A probe closer to the mass slide impact was desirable, but it could not be secured. The wave impact and reflection on the upper face of the dam were also determined in the laboratory experiments. This was done by measuring both the wave height and the pressure exerted on the wall. Figure 3 shows a gauge and the pressure transducers placed on the upper face of the dam.
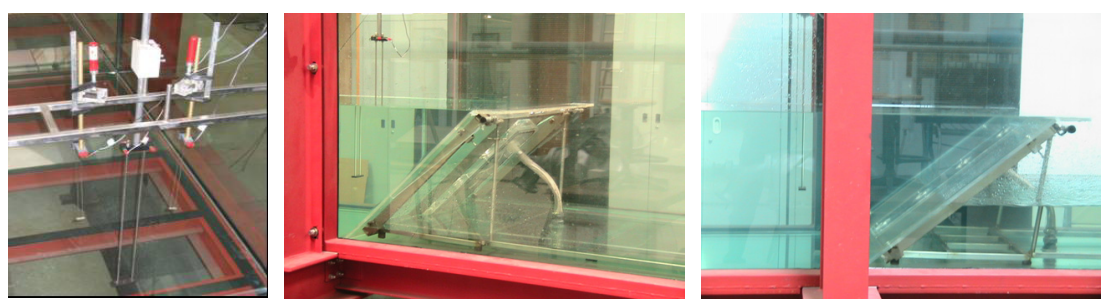

Figure 3: A gauge for water level measurements, the dam and the pressure transducers on its upper face.

The laboratory study of the wave characteristics and the hydrodynamic effects caused by landslides was based on a test matrix that included 18 different conditions. For all experiments, the successive positions of the sliding blocks were calculated using equation (2) and the images processed by video recordings. 


\subsubsection{Sliding mass velocities into the water mass and resulting waves}

The velocity was calculated with equation (2). Figure 4 below shows the variation of the slide mass velocity during the fall calculated by this equation. It can be concluded that different velocity diagrams of landslide fall were produced: parabolic (E01-E12), quasi-linear (E13-E17) and quasi-sinusoidal (E18). Sudden descending variations occurred due to the reservoir water level, which is not deep enough to decelerate the sliding mass.

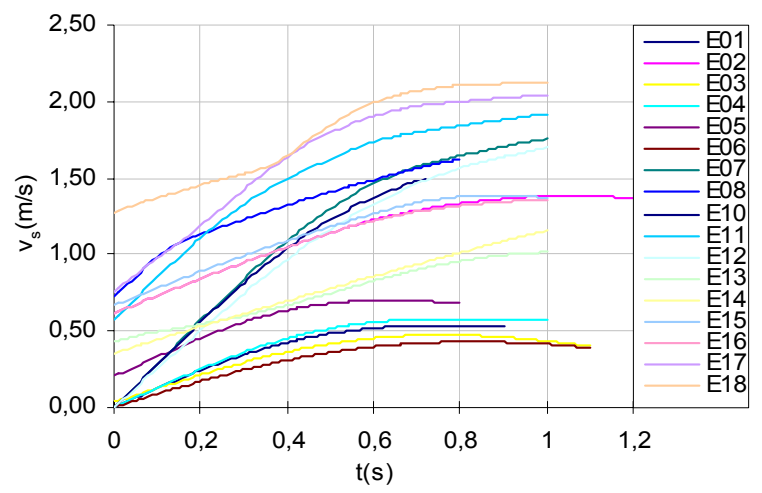

Figure 4: $\quad$ Slide mass velocity curves during sliding (Carvalho et al. [7]).

In general, a higher initial position of the centre of gravity corresponds to a higher initial velocity, and a higher slope corresponds to a more pronounced increase in slide velocity. The relevant parameters governing slide velocity, and so wave generation, consist of: the mass of the sliding blocks, the still water level in the reservoir, the slope and the initial position of the mass centre of the sliding blocks. Figure 5 illustrates the water level measurements at the five gauges in the tests: E03 and E11.

\subsubsection{Numerical propagation of the resulting waves and comparisons with laboratory data}

The results of two distinct numerical models, based on different mathematical formulations, were compared with physical data obtained at the probes installed along the reservoir. The first model is based on the Reynolds-averaged NavierStokes equations governing the motion of the mean 2D incompressible flows in the $x-z$ plane, in which the free surface is described using a refined VolumeOf-Fluid (VOF) method (see Carvalho, [5], and Carvalho and Antunes do Carmo, [6], for mathematical and numerical details of this model).

The second model solves an extension of the modified Boussinesq equations, which are considered a suitable mathematical model for obtaining the characteristics of a wave caused by a landslide and its propagation within the reservoir (Antunes do Carmo et al. [3]; Antunes do Carmo and Seabra Santos, [4], and Carvalho and Antunes do Carmo, [6], for mathematical and numerical 
details of this model). Figure 6 shows a comparison of the numerical results of both models and laboratory data of the reservoir water level variations in test E14 at $4 \mathrm{~m}$ and $6 \mathrm{~m}$ from the slide mass falling point.

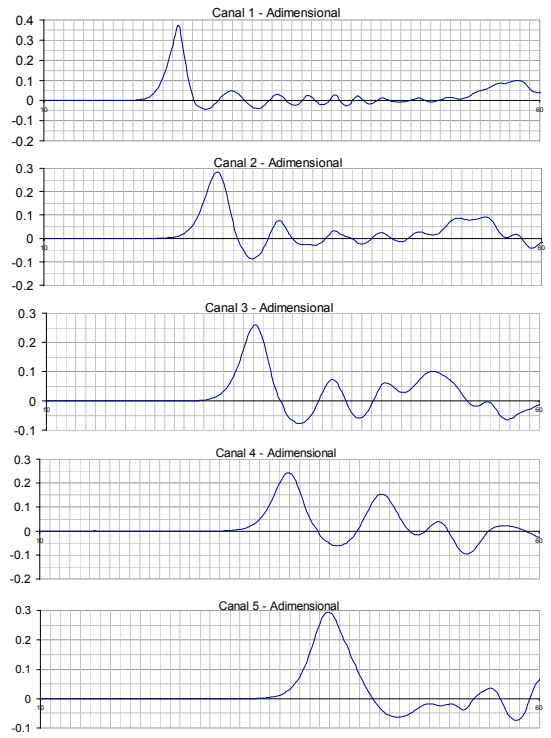

a)

Figure 5: Water level measurements $\left(h / h_{0} v s t \sqrt{g / h_{0}}\right)$ at gauges no.1 to no. 5 ( $2 \mathrm{~m}, 4 \mathrm{~m}, 6 \mathrm{~m}, 8 \mathrm{~m}$ and $10 \mathrm{~m}$ upstream of the bank slope toe): a) E03, and b) E11.

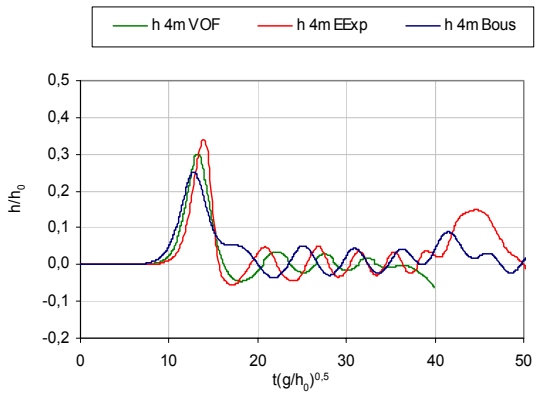

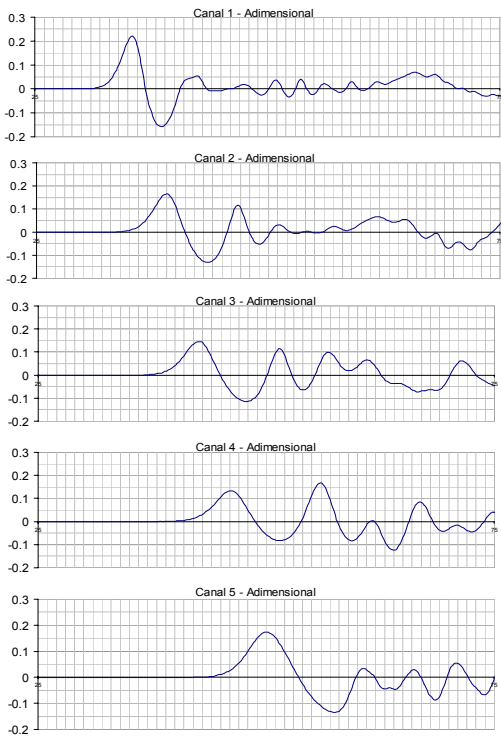

b)

Figure 6: Reservoir water level variations in test E14 at $4 \mathrm{~m}$ and $6 \mathrm{~m}$ from the slide mass falling point. Comparisons between data obtained in laboratory and numerical results of two numerical approaches.

The numerical results show an acceptable agreement with experimental data. It may be concluded that the numerical simulations are strongly dependent on the 
definition of the inflow boundary condition, which in its turn depends on the velocity variation of the sliding mass.

\section{Analyses of probable maximum floods vs extreme climatic events}

\subsection{Physical damage caused by floods}

Physical damage caused by floods is grouped according to its effects: $i$ ) to dams and reservoirs; $i$ ) to banks and fluvial constructions, and iii) along valleys. Dams and reservoirs located in river channels are at high risk of flooding. Dams could be vulnerable particularly if there is limited spillway capacity. If the spillway and gates are inadequate, there is a risk of the dam collapsing, causing yet another disaster and enormous additional damage from the spillage of the stored water. If the dynamic forces of the flood are strong enough they can cause erosion around the banks and any installations, like intakes, spillways, engine houses, etc. Potential damage is a great concern to people, buildings and infrastructures, as well as to economic, environmental and heritage assets that may be located in the valleys. Disaster reduction policies and measures need to be implemented, with a two-fold aim: to enable society to be resilient to natural hazards while ensuring that development efforts do not increase vulnerability to these hazards. A fundamental condition for disaster preparedness is the availability of risk assessments and properly-functioning early warning systems that deliver accurate and useful information promptly and reliably to decision-makers and the population at risk. While natural hazards cannot be prevented, integration of risk assessment and early warnings, together with prevention and mitigation measures, can prevent them from becoming natural disasters.

\subsection{Evaluating flood hazards and risk mapping}

Flood hazard analysis requires the determination of flood zones and channels affected based on: duration of the phenomenon, runoff, and $M P F=$ maximum probable flood levels. This information is used to develop flood risk maps. The superimposition of risk maps over diagrams of the water supply system will show structures that are likely to be affected by flooding.

The management of risks associated with disasters arising from extremes of water, weather and climate is becoming more and more essential. Any effective reduction of the loss of lives and property rests significantly on the following three pillars: 1) Assessment of hazards and population vulnerability to disasters; 2) Early warning, forecasting and prediction, and 3) Population awareness and preparedness to adequately respond to risks and prevent disasters.

\section{Conclusions}

Different approaches are suggested to draw together researchers, managers and users to develop processes, practices and instruments. For this a number of rules should be kept in mind to systematize and to prepare guidelines to help in the 
design and operating of reservoirs involving the construction of large dams, as well as for emergency planning and risk management procedures for both dam owners and civil defence authorities. A methodology is suggested for studying the hydrodynamic effects on a dam considering both the real bathymetry of the reservoir and the geometry of its upper face. In terms of laboratory measurements and numerical results on the wave characteristics formed when large masses of soil or rock fall into a reservoir, it has been shown that numerical simulations are strongly dependent on the definition of the inflow boundary condition, which in turn depends on the velocity variation of the sliding mass.

General guidelines to manage properly the dam-reservoir system, based on relevant non-dimensional parameters, are currently in preparation and will be presented at the conference.

\section{References}

[1] Almeida A.B., Ramos C.M., Santos M.A. \& Viseu T., 2003. Dam Break Flood Risk Management in Portugal (book). LNEC, Lisbon. ISBN: 97249-1979-X.

[2] Almeida A.B. \& Viseu T., 1997. Dams and valleys safety. A present and future challenge. Almeida A.B. and Viseu T. (Eds), Dams and safety management in downstream valleys, A.A. Balkema, Rotterdam, pp. 0325.

[3] Antunes do Carmo J.S., Seabra Santos F.J. \& Barthélemy, E., 1993. Surface Waves Propagation in Shallow Water.... Int. J. Num. Meth. in Fluids, Vol. 16, 447-459.

[4] Antunes do Carmo J.S. \& Seabra Santos F.J., 1996. On breaking waves and wave current interaction in shallow water... Int. J. Num. Meth. in Fluids, Vol. 22, 429-444.

[5] Carvalho R.F., 2002. Hydrodynamic actions on hydraulic structures... $\mathrm{PhD}$ thesis, University of Coimbra, Portugal.

[6] Carvalho R.F. \& Antunes do Carmo J.S., 2006. Numerical and experimental modelling of the generation and propagation of waves caused by landslides into reservoirs... Taylor \& Francis / BALKEMA, Vol. 1, 483-492. ISBN 0-415-40810-5.

[7] Carvalho R.F., Antunes do Carmo J.S. \& Pestana A., 2006. Waves caused by landslides into reservoirs and their impacts on dams. J. Matos \& $\mathrm{H}$. Chanson (Eds), Rep. CH61/06, Div. Civil Eng., The University of Queensland, Brisbane, Australia. ISBN 1864998628.

[8] Fritz H.M., Hager W.H. \& Monor H.-E., 2004. Near Field Characteristics of Landslide Generated Impulse Waves. J. Waterway, Port, Coastal, and Ocean Eng., pp. 287-300.

[9] Hanna, Y.G. \& Humar, J.L., 1982. Boundary element analysis of fluid domain. J. of the Engineering Mechanics Division, Vol. 108, No. EM2, 436-449.

[10] Lynett P. \& Liu P.L.F., 2005. A numerical study of the run-up generated by three-dimensional landslides. J. Geo. Res.-Oceans 110 (C3): Art. No. C03006 MAR 82005. 